Sharif University of Technology
Scientia Iranica
SCIENTIA
I RAN I CA

Research Note

\title{
Towards resilient and sustainable cities: A conceptual framework
}

\author{
M. Tabibian ${ }^{\mathrm{a}, *}$ and S. Movahed ${ }^{\mathrm{b}}$ \\ a. Department of Urban Planning, University of Tehran, Iran. \\ b. Department of Urbanism, Qazvin Branch, Islamic Azad University, Qazvin, Iran.
}

Received 1 September 2015; received in revised form 6 February 2016; accepted 30 May 2016

\section{KEYWORDS}

Resilience;

Sustainability;

Mashhad City;

Water resources.

\begin{abstract}
Cities are complex and dynamic meta-systems in which technological and social components interact with each other. A variety of hazards threaten cities; thus, planning for resilience in the face of urban disaster is important. We are just beginning to realize the scope and magnitude of the challenges inherent in making our cities resilient to threats from natural hazards and terrorism. To meet these challenges, a national resilientcities initiative aims at the vision of the resilient city as the goal that covers all types of hazard mitigation. To succeed, this initiative will require changes in national disaster policy, funding for urban systems research, support for advanced education program, and active collaboration among the city professions. One of the natural hazards to which cities should be resilient is drought that is resulted from climate change. The city of Mashhad, which has faced water crisis in recent years, is selected as a case study. By analyzing the status of water resources and their changes during the periods of growth and development of the city, its function in resilience and sustainability is measured. Also, necessary strategies for improving the water resources condition in order for the city to become resilient and sustainable are proposed.
\end{abstract}

(C) 2016 Sharif University of Technology. All rights reserved.

\section{Introduction}

With the September 11, 2001 attacks, New York City sustained an iconic urban systemic shock. Three years after the monumental storm of Hurricane Katrina, only an estimated two thirds of the pre-Katrina population has remained and large areas of the city sit vacant. New Orleans as a whole is struggling to develop the capacity to adapt and to rebound [1]. While these two examples might not seem comparable, they both point to the importance of designing cities that are resilient.

Rapid urbanization and growing mega-cities point to a need for smarter and more resilient cities that possess the capacity to withstand the shocks of popula-

*. Corresponding author.

E-mail addresses: tabibian@ut.ac.ir (M. Tabibian);

Movahed.sepide@gmail.com (S. Movahed) tion growth, world economic crises, rapid demographic shifts in population, and environmental catastrophes. In addition, resilience must also be displayed in terms of events that have a more long-term horizon, such as when we see cities in decline. Cities are complex and interdependent systems, extremely vulnerable to threats from both natural hazards and terrorism. The very features that make cities feasible and desirable, i.e. their architectural structures, population concentrations, place of assembly, and interconnected infrastructure systems, put them at a high risk to floods, earthquakes, hurricanes, and terrorist attacks. Increasing support for the notion of resilient cities is found in the hazard mitigation literature. Godschalk et al. [2] proposed a sustainable mitigation policy system whose goal was to develop resilient communities capable of managing extreme events. Many other recent disaster studies also call for the development 
of resilient communities. Beatly [3] notes that a sustainable community is resilient-seeking to understand and live with the physical and environmental forces present at its location. Vale and Campanella [4] explore the historical meanings of resilience and urban trauma. Despite such interest in the concept of resilient communities, few studies have formulated systematic principles of resilience and applied them at city scale. Regarding the above statements, it is essential to understand why a city must be resilient and how cities, as complex systems, can be resilient. Building capacity for resilience may be a daunting task when one considers the multitude of components, processes, and interactions that take place within and beyond physical, logical, and virtual (cyberspace) boundaries of a city. The main aim of this paper is to introduce a conceptual framework for launching the national initiative of a resilient city. This framework entails changes in national disaster policy; funding for basic and applied urban systems research; support for advanced education program; and active collaboration among the city planning, design, and construction professions. In order to achieve the main objective of the research, the concept of resilient city, its importance, and its relationship with other concepts such as sustainability are discussed. By explaining the urban resilience and sustainability framework, the dimensions of these concepts are determined. Therefore, the environmental dimension as one of the common aspects of these concepts has been selected for review in this article. This research concentrates on natural resources conservation as a significant issue in the environmental dimension of resilience and sustainability. Hence, resilience of Mashhad against drought through the assessment of its water resources as a part of natural resources is analyzed as a case study. Finally, the analysis results of three objects; i.e., the relationship between resilience and sustainability; Mashhad water resources; and the relationship between water resources management, urban sustainability, and resilience; are discussed.

\section{Methodology}

\subsection{Delimitation}

For determining the study limits, the current research considered only one of the main elements of resilient and sustainable cities, i.e. their environmental aspect. While other dimensions of resilience and sustainability are proposed, environmental dimension is considered more carefully in the research process because of the importance of ecological issues of cities.

\subsection{Operationalization}

In order to implement the concepts and principles extracted from the literature survey in the second section, water resources and natural water circles are considered as one of the main proposed issues in environmental dimension and for achieving urban sustainability and resiliency. The following factors are evaluated as effective variables on water resources of Mashhad:

1. Growth and development of the city;

2. Impermeable surface;

3. Drainage patterns;

4. Water basin exit;

5. Springs, aqueducts, and wells.

\subsection{Material}

The current research can be divided into two sections regarding methodology; the first section was done through a descriptive and analytic method. Through performing a library study, reviewing literature, and analyzing different views about resilient and sustainable cities, required information about all features and relations between these concepts were gathered. In the second section, required information about the situation of Mashhad City and its water resources was gathered through field studies and referring to the related organizations. Thorough statistical analysis of achieved information, hydrological state of this city (maintenance of water resources and circles) and its role in sustainability and resiliency were measured. Therefore, through scrutinizing the relation between sustainability and resiliency and analyzing the principles proposed in them, the intention of this research, unlike other articles that are based on theoretical discussions, is to analyze achieved information in the given case study and find practical strategies.

\section{About resilient and sustainable cities}

\subsection{What is a resilient city?}

When resilience is the aim, it is crucial to understand what the term means and what a resilient city should comprise. As may be expected, there are many definitions of a resilient city, ranging from very narrow to very broad, reflecting different cultural values.

One feature that always seems to be present is 'strength'-making communities and cities stronger against establishing forces that put their citizens and structures at risk. Generally, resilience is also linked to sustainability principles.

To the World Bank, for example, "a resilient city is one that is prepared for existing and future impacts, thereby limiting their magnitude and severity".

The world Urban Forum's Vancouver Working Group takes a more confined approach and links resilience to the ability of a city to expand its production base (e.g. from depending on one industry to attracting and embracing a broader base and economy). 
Yet, another definition links resilience directly to peak oil and defines resilient cities as the cities "that can last, make through crises and possess inner strength and resolve as well as appropriate built form and physical infrastructure" [5].

The European Environment Agency (EEA) sees a resilient city as an "urban ecosystem" that is dynamic; consuming, transforming, and releasing materials and energy in an adaptive way and interacting with other ecosystems, tackling mitigation and adaptation efforts, and addressing quality of life through better and greener urban planning [6].

As a final and comprehensive approach, International Council for Local Environmental Initiatives (ICLEI) in the Bonn Resilient Cities Conference defines a resilient city as [7]:

- A city that supports the development of greater resilience in its institutions, infrastructures, and social and economic life;

- Resilient cities reduce their vulnerability to extreme events and respond creatively to economic, social, and environmental changes in order to increase their long-term sustainability;

- Resilient city activities are sensitive to distinctive local conditions and origins. Efforts undertaken to prevent crisis or disaster in one area should be designed in such way as to advance the community resilience and sustainable development in a number of areas;

- Resilient cities define a comprehensive 'urban resilience' concept and policy agenda with implications in the fields of urban governance, infrastructure, finance, design, social and economic development, and environmental resource management;

- Local resiliency with regard to disasters means that a locale is able to withstand an extreme natural event without suffering devastating losses, damage, diminished productivity, or decline in quality of life and without a large amount of assistance from outside the community [8];

- A resilient city is a sustainable network of physical systems and human communities.

Physical systems are the constructed and the natural environmental components of the city. The physical system acts as the body of the city; its bones, arteries, and muscles. During a disaster, the physical system must be able to survive and function under extreme stresses. A city without resilient physical systems will be extremely vulnerable to disasters. Human communities are the social and institutional components of the city. They include the formal and informal, stable and ad hoc associations that operate in an urban area: schools, neighborhoods, agencies, organizations, task force, and the like. In sum, the communities act as the brain of the city, directing its activities, responding to its needs, and learning from its experience. During a disaster, the community networks must be able to survive and function under extreme and unique conditions. If they break down, decision making falters and response drags. Social and institutional networks exhibit varying degrees of organization.

Resilient cities are constructed to be strong and flexible, not brittle and fragile. The lifeline systems of roads, utilities, and other support facilities are designed to continue functioning in the face of rising water, high winds, shaking ground, and terrorist attacks.

\subsection{Why is resilience important?}

Resilience is important for two reasons: First, because the vulnerability of technological and social systems cannot be predicted completely, resilience - the ability to accommodate change gracefully and without catastrophic failure - is critical in terms of disaster [9]. If we knew exactly when, where, and how disaster would occur in the future, we could engineer our systems to resist them. Since hazards planners must cope with uncertainty, it is necessary to design cities that can effectively cope with contingencies.

Second, people and property should fare better in resilient cities struck by disasters than in less flexible places faced with uncommon stress [10,11]. In resilient cities, fewer buildings should collapse, fewer power outages should occur, fewer households and business should be put at risk, fewer deaths and injuries should occur, and fewer communications and co-ordination breakdowns should take place.

Some skeptics argue that the pursuit of community resilience is laudable but unpractical using a conceptual framework based on the theoretical models of mitigation, recovery, and structural cognitive interaction. Tobin [12] examined data from the State of Florida to assess the possibility of developing sustainable, resilient communities, analyzing the state as a whole rather than considering any individual cities. Tobin concluded that major (unlikely) changes in political awareness and motivation would be necessary to overcome obstacle to resiliency and sustainability from Florida's existing demographic traits, spatial patterns, and hazard conditions.

\subsection{Qualities that characterize a sustainable city}

A sustainable city is one that is reducing its ecological footprint, its resource consumption, land consumption, and waste production, whilst simultaneously improving its quality of life (its health, housing, work opportunity, and livability). Thus, the three characteristics of a sustainable city are [13]:

- The city "recognizes" there are real limits to its eco- 
logical footprint that it cannot continue to expand its use of energy, water, and materials;

- The city sees its innovations in economic and social development to be essential but not divorced from the need to reduce its footprint. Most programs must do more for people with less from the earth;

- The city has a governance system that rewards the sustainability innovation which integrates the contributions of the business, community, and government. They rejoice in the creative expressions of its artist in expanding sustainability sensitivities that build its particular sustainability approaches on the identity and sense of place in the city and communicates it for all other cities to learn from.

\section{Framework for resilience and sustainability}

\subsection{Resilience and /or sustainability}

Resilience and sustainability are not mutually exclusive, but should be seen as powerful companions to shape both the future planning and daily management of cities. Sustainability represents the end goal that ward-thinking cities are pursuing to secure a good quality of life for all people, today and future, through strong and prosperous communities, a vibrant and stewardship of both local and global environmental assets. Resilience works within the context of longterm sustainability objectives, but specifically embraces the turbulence of daily life. Resilience is about learning with the spectrum of risks that exists in the interface between people, the economy, and the environment and in maintaining an acceptable stability or equilibrium in spite of continuously changing circumstances. Resilience also addresses the independencies between systems and minimizes unforeseen 'gaps' in risk management [14]. Therefore, system planning and design should seek to measure performance against both resilience and sustainability indicators.

There are two more points that a resilient city needs to take into consideration. One is that becoming resilient is a process that demands continual improvement and that, by definition, is an ever-evolving effort; this process is adaptive because it aims at a continual improvement of the decisions taken (e.g., in rethinking urban planning, in increasing local renewable energy supply, or in putting alert systems in operation) and the action implemented. The second point that a resilient city needs to consider is that resiliency should be embedded in the context of sustainability. Resiliency solutions, which are largely addressed through climate change adaptation, climate change mitigation, and disaster risk reduction, need to contribute to the amelioration of environmental degradation and realities of poverty and inequality, as shown in Figure 1. Otherwise, solutions will not be effective in long term [15].

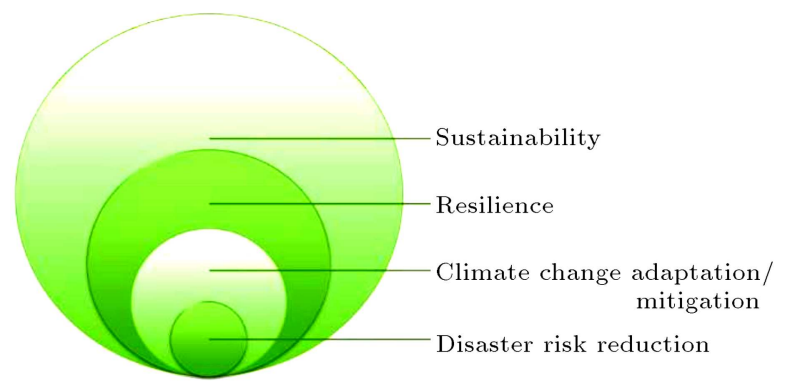

Figure 1. The context of resilience [15].

As Figure 1 shows, addressing disaster risk reduces vulnerability, as do sustainable measures to deliver climate change (and mitigation, at least, in long term). These two fields - disaster risk management and climate change adaptation - are becoming closer in their approaches, as disaster risk management moves to include, along with reaction, prevention as a major objective [16]. These efforts enhance resilience of a community or city (the second biggest ball) and they contribute to sustainability and to the longterm prevalence of communities, cities, and human biodiversity, only if they are shaped with sustainability criteria (the biggest ball).

\subsection{The cost and benefits of being resilient}

There is abundant literature on the economic costs and benefits of adaptation and mitigation, whereas the cost of resilience remains more 'obscure' and more difficult to define. One smart way to reduce the need for dedicated adaptation funding and to efficiently use resources to reduce vulnerability in cities is to incorporate climate change, adaptation, and resilience criteria into present investments on urban fixed assets (many of which stem from private sector). The concept of 'resilience upgrading' looks for enhancing resilience of the city by increasing its performance - its ability to deliver a high quality of life and quality services to its residents [15]. Instead of approaching the topic of adaptation and disaster risk from the perspective of 'escaping risks', it rather looks at the benefits that smart, climate-proof investments can deliver to the city and to the service or product providers, as shown in Figure 2(a) and (b).

The European Union's 2020 strategy is centered on growth. It aims to achieve smart growth, sustainable growth, and inclusive growth; growth in a world that is dominated by unsustainable practices, where the global population depletes natural resources and ecosystem services faster than the planet can replenish them, as a major challenge. The symbolism used by the global footprint network to describe the problem of growth and unsustainable use of resources is an effective way to transmit the message: Today, we consume the resources equivalent to 1.5 planet earths that is, it takes "the earth one year and six months to 


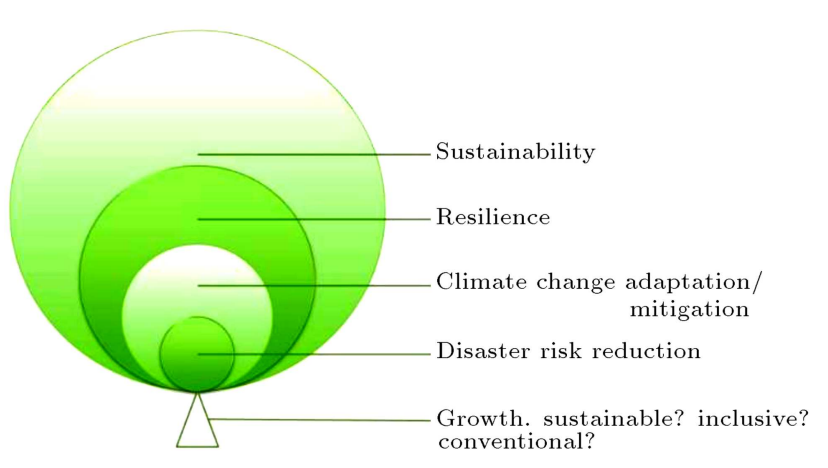

Figure 2(a). Striking a balance between growth, sustainability, resilience, climate change adaptation/mitigation, and disaster risk reduction [15].

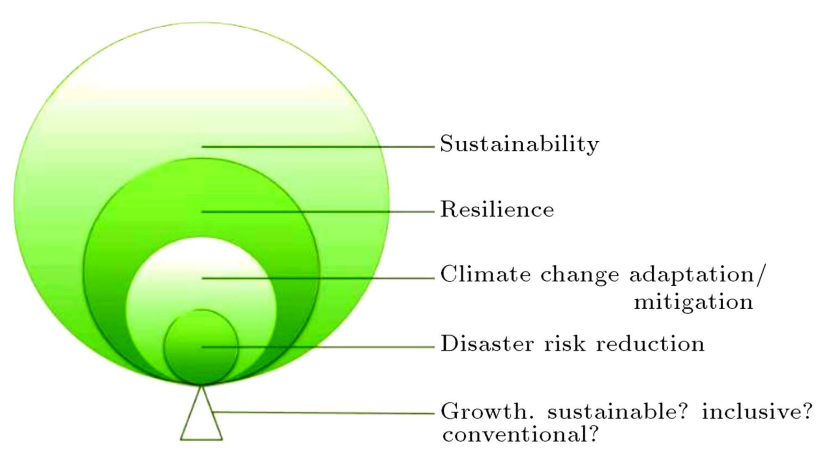

Figure 2(b). Framework for resilience work at the local level [15].

regenerate what we used in a year" and to absorb the waste we generate - and by year 2030, we are likely to need two planet earths [17].

The complicated systems of cities and regions need management on various levels. To name but a few, the economy, the social sector, and personnel are all managed in one way or another. Managing tasks individually and sectorally, however, is most often inefficient and leads to increased workload and weak results. Re-organizing and integrating existing practices, plans, and strategies with one steering wheel, i.e. the Integrating Management System (IMS), will systemize the work, boost efficiency, and provide a multitude of positive outcomes. It will direct all available resources towards the goals defined and secure the transparency and democratic principles of decision making. In the IMS, the unsuccessful effort in running several parallel management systems can be transformed into sustainability. The IMS consists of five major steps repeated in annual cycles. Although the system follows an annual cycle, full revision will be required once per election period, and preferably at the outset [15].

\subsection{Dimensions of resilience and sustainability}

In recent years, different studies have considered resilience dimensions and the proposed criteria and prin- ciples. Cutter et al. [18] proposed a series of indices for measuring basic features of communities considering resilience improvement in 6 dimensions. United Nations University Institute of Advanced Studies [19] and Sharifi and Yoshiki [20], respectively, explained indices and criteria for developing resilience in its main forming dimensions. Therefore, in Figure 3, which is achieved by reviewing references and researcher's processes, dimensions of resilience and the proposed indices in each dimension are listed for codifying of urban resilience framework.

Different research works can also be named for sustainability and its dimensions and factors. Bahreini [21] suggested the main issues in achieving sustainable urban development. Pourjafar et al. [22] and the Department of Economic and Social Affairs of the United Nations [23] also analyzed sustainable urban development and main factors of sustainability. Reviewing sustainability literature shows their common aspect in explaining main dimensions of sustainability according to Figure 4. Achieving sustainable cities needs combining five main factors: social development with the aim of social justice, economic development with the aim of economic survival, environmental sustainability with the aim of ecological balance, organizational development with the aim of planning integration, and physical sustainability with the aim of morphological balance.

Comparative analysis of Figures 3 and 4, which separately demonstrate the main dimensions and the most important forming indicators of resilience and sustainability framework, can lead to common aspects of resilience and sustainability. As it is observed in the given figures, economic, social, environmental, and organizational dimensions are the most important dimensions for regulating a framework for resilient and sustainable cities. In this research, environmental dimension has been selected as the most important factor which resiliency and sustainability emphasize. This study focuses on the state of water resources as a part of the environmental dimension in Mashhad.

\section{Case study: Mashhad}

Mashhad is the second large city of Iran, covering $328 \mathrm{~km}^{2}$, located in Mashhad Plain and Kashfrood Basin between mountain chains of Kopehdagh and Hezarmasjed in northern areas and Binaloud altitudes in southern areas. This city has been developing rapidly and vastly in the recent decades [24]. Figure 5 shows geographical details of this region and its surrounding altitudes.

One of the most important effective factors on urban water resources is rapid and widespread growth and development of cities. The analysis of demographic 


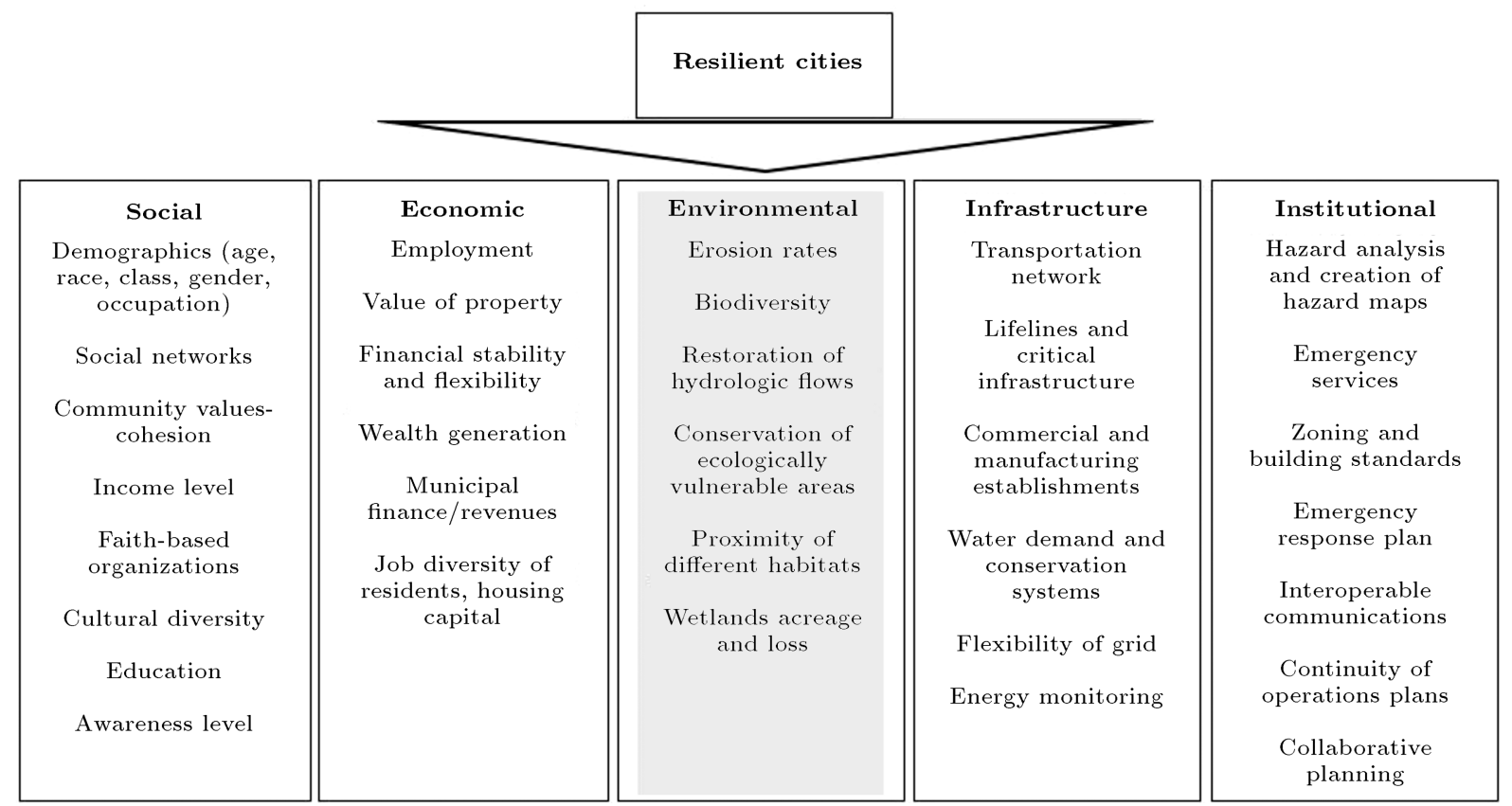

Figure 3. Urban resilience framework.

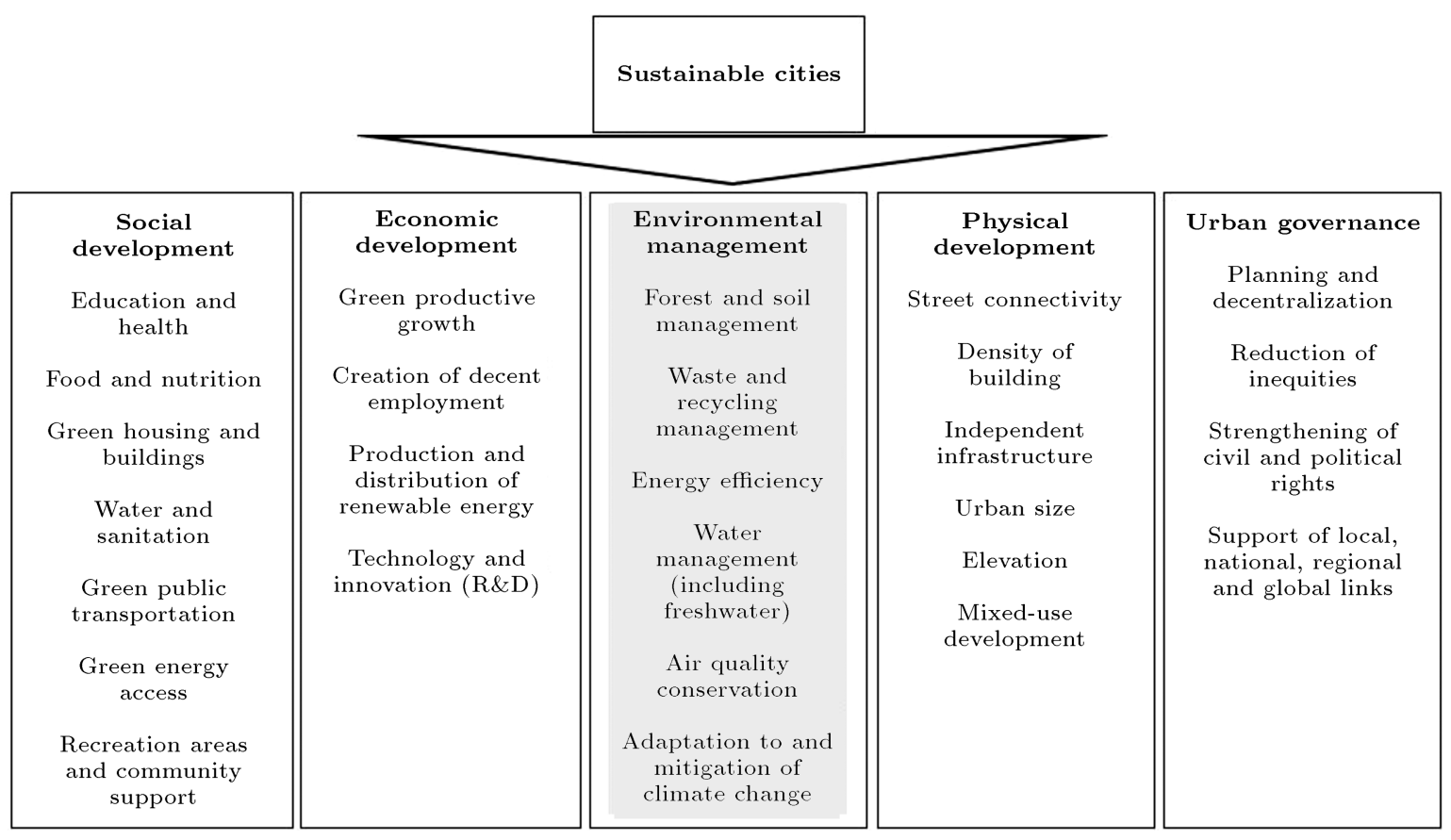

Figure 4. Urban sustainability framework.

changes and physical development of Mashhad, as shown in Figure 6, indicates that unplanned rapid growth of this city in the recent decades (1956-2011) has caused environmental crisis, especially in the case of surface and underground water resources.

\subsection{Mashhad growth and development analysis}

As Table 1 and Figure 7 show, and according to the first formal census in 1956, the population of this city consisted of 242000 citizens and its size was $16 \mathrm{kM}$. In this period, Mashhad slowly developed, relatively centralized, and had a relatively high density of 151 citizens per 1 hectare. In the next years, urban growth and development took the lead of the population size, i.e. urban density in 1966 reduced by 124 citizens per 1 hectare. Unplanned rapid growth and development between 1966 and 1977 and their problems resulted in comprehensive urban plan development in 1967. Although the anticipated urban development in this 
Table 1. Demographic changes, size, and population density of Mashhad (1956-2011) [25,26].

\begin{tabular}{cccccccc}
\hline Year & $\mathbf{1 9 5 6}$ & $\mathbf{1 9 6 6}$ & $\mathbf{1 9 7 6}$ & $\mathbf{1 9 8 6}$ & $\mathbf{1 9 9 6}$ & $\mathbf{2 0 0 6}$ & $\mathbf{2 0 1 1}$ \\
\hline Population (person) & 242000 & 409000 & 667000 & 1463000 & 1887405 & 2430800 & 2772287 \\
Area (hectare) & 1600 & 3300 & 7800 & 22000 & 24499 & 29377 & 30000 \\
Growth percent & 2 & 5.39 & $5 / 01$ & 8.17 & 2.58 & 2.56 & 2.66 \\
Population density & $151 / 2$ & 124 & $85 / 5$ & 66.5 & 77.3 & 82.74 & 92.4 \\
\hline
\end{tabular}

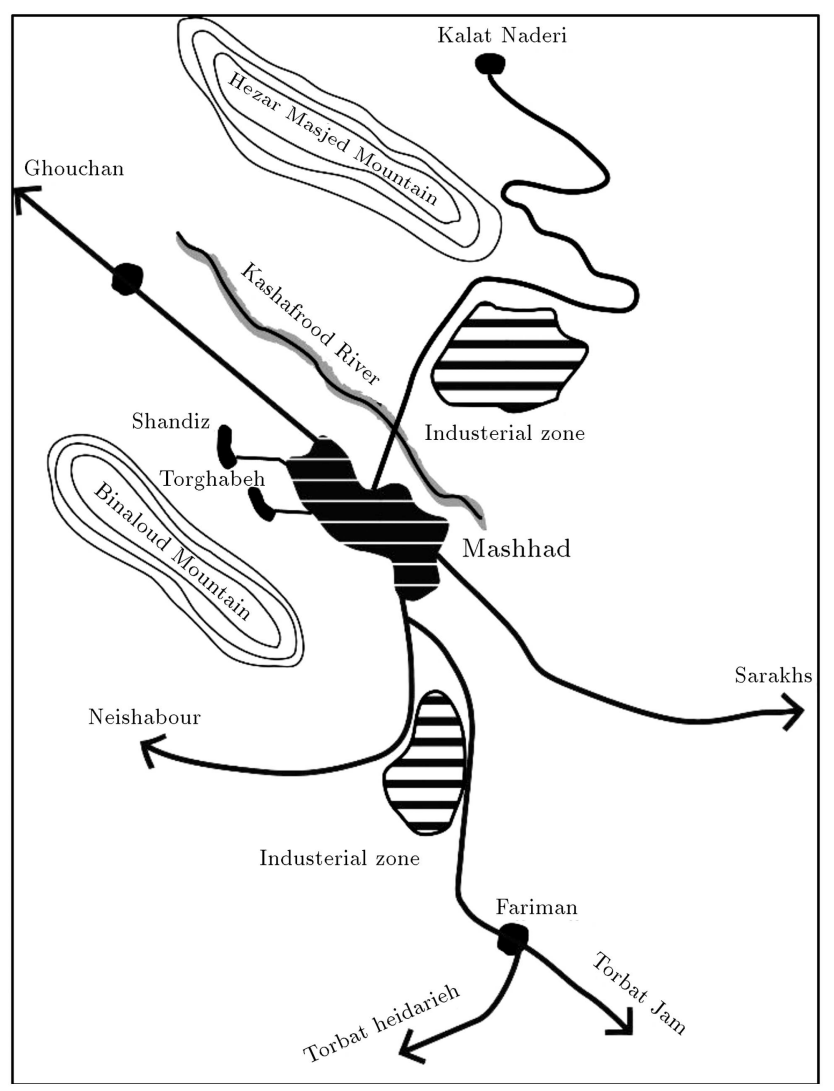

Figure 5. Geographical image of Mashhad.

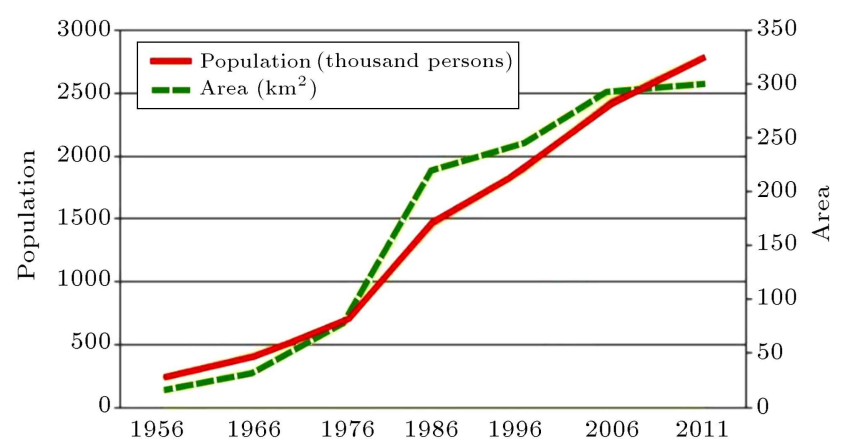

Figure 6. Demographic changes and physical development of Mashhad.

plan was about $170 \mathrm{kM}^{2}$ until 1991, its size increased over $220 \mathrm{kM}^{2}$ in 1986 , i.e. 5 years before the predicted period. Moreover, the population density between 1976 and 1986 reached the lowest level, i.e. 66.5 citizens per 1 hectare. Accordingly, Mashhad grew very rapidly and
Table 2. Land-use and geomorphologic unit changes due to urban development $[28,29]$.

\begin{tabular}{ccc}
\hline $\begin{array}{c}\text { Land } \\
\text { use/geomorphology } \\
\text { unit }\end{array}$ & $\begin{array}{c}\text { Area } \\
\text { in } \mathbf{1 9 6 6} \\
\left(\mathbf{k m}^{\mathbf{2}}\right)\end{array}$ & $\begin{array}{c}\text { Area } \\
\text { in } \mathbf{2 0 0 9} \\
\mathbf{( \mathbf { k m } ^ { 2 } )}\end{array}$ \\
\hline Alluvial fan & 137.4 & 19 \\
Compact plains & 251.68 & 171.08 \\
Agricultural land & 107.36 & 45.63 \\
Uncultivated Land & 132.23 & 19.41 \\
\hline
\end{tabular}

followed a dispersed and sprawling growth pattern in all periods of urban growth.

\subsection{Urban development and changes in water cycles and resources}

Mashhad urban development has exerted negative impacts upon its water resources due to negligence of environmentally sustainable development principles. This study highlights these impacts upon surface and underground water.

\subsubsection{Surface water resources}

Urban development significantly impacts upon surface water resources from different dimensions. Surface water resources of Mashhad have changed due to three main causes: (1) Extensions of impermeable levels as the result of further urban land development; (2) changes of natural drainage patterns as the result of constructions; and (3) pressures on water basin exit. They are discussed in the following sections.

Impermeable surface extensions and hydrologic imbalances. According to Table 2, over 50 percent of agricultural lands and large areas of uncultivated lands, compact plains, and alluvial fans, including permeable areas, have transformed into impermeable urban lands due to urban development, which in turn causes changes of watercourses hydrology, runoff size, and the volume of incoming water drainages and underground water tables $[28,29]$.

Changes of drainage patterns. A large number of natural waterways have been removed, or blocked, or they have changed their routes due to urban development of Mashhad. Indeed, the main natural channels are afflicted with a limited space and change their ways. 


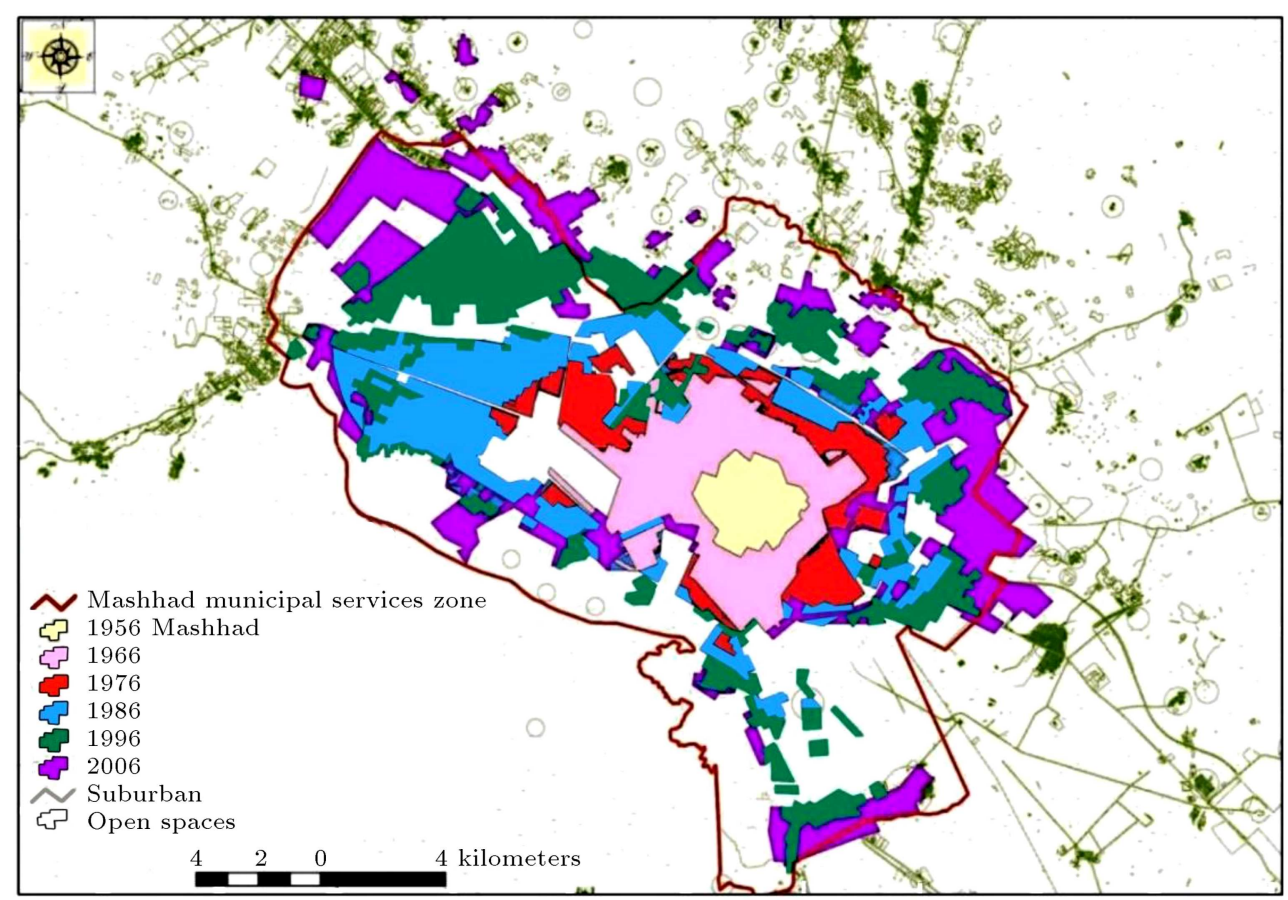

Figure 7. Urban development of Mashhad in different periods [27].

Even, they are likely blocked, their width is reduced, or they are unessentially deviated due to embankment and construction building. 227 sub-channels with a length of $140 \mathrm{~km}$ and 43 main channels with a length of $82.9 \mathrm{~km}$ were blocked or significantly changed due to urban development [29]. Indeed, urban design structure and urban drainage system in the studied developed areas are not significantly in agreement with natural drainage patterns. In other words, Mashhad urban development has happened without any environmental and morphological consideration and it causes environmental crisis in this metropolis.

Pressures on water basin exit. Development of constructions and residential context in suburbs and river basin exits makes the main waterway bottleneck compressed in entry of plains and reduces width of the channels and watercourses [30]. This creates insufficient space for movement of floodwaters and causes cyclic floods.

\subsubsection{Underground water resources}

Mashhad underground water table, including $2200 \mathrm{~km}^{2}$ of areas, is one of the largest aquifers in Iran [31]. These waters are used by different resources including springs, aqueducts, and wells.

Springs. Mashhad plain springs were large in number, which have reduced due to sprawling urban development and excessive use of water resources. 337 springs exist at the present time and about 14 springs are located in Mashhad zone. Only one of these cases flows permanently over 9 months of each year, which is used for drinking [32].

Aqueducts. There were 162 aqueducts in Mashhad city and its suburbs. 88 aqueducts, containing 10736 liters of water per second, have moved into infrastructures and have been inactivated. Today, two aqueducts, containing 320 liters of water per second, are used for urban water consumption [33]. The most devastating impact of the urban development upon aqueducts is inattention to their limits at the time of construction activities, which destroys aqueducts and eliminates them from water supply cycle. Accordingly, they are used for urban wastewater.

Wells. Because of elimination of aqueducts from water supply cycle, methods such as deep well and semi-deep well digging and dam construction were replaced for drinking water supply to Mashhad. Unlike these new methods of water supply, wells are greatly consistent with local conditions and sustainable development principles, because they do not rely on electric energy and oils. Additionally, they do not qualitatively and quantitatively harm underground water since they are gradually used. As Figure 8 shows, excessive use of water in Mashhad plain surface along with rapid development of urbanism without any consideration of environmental sustainability principles is an indication of marked reductions in Mashhad plain underground waters. Underground water decreased by 7 meters from 2003-2004 to 2011-2012, i.e. 1-meter reduction per one year. Consequently, Mashhad plain as the largest 


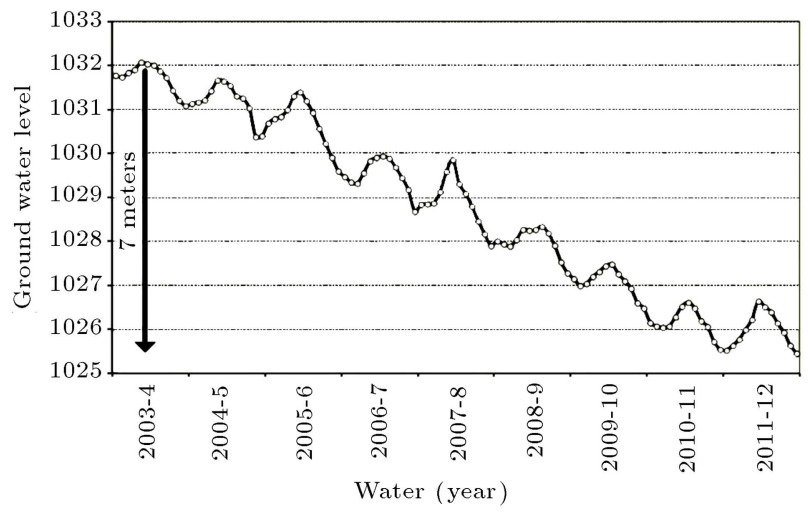

Figure 8. Mashhad plain underground water hydrograph during 10 years [34].

aquifer of Iran in the past is presently in the most critical state among Iran aquifers.

\section{Results and discussion}

\subsection{Analysis of the relationship between resilience and sustainability}

With respect to the above-mentioned statements, resilience is one of the crucial concepts for operationalizing sustainability, which follows a set of social objectives, social justice, and environmental perfection. Resilience is a conceptual and modelling framework that indicates the phenomena which facilitate or inhibit the achievement of normative sustainability goals. For instance, as mentioned in the above definitions, one of the urban sustainability cases is natural resources use reduction and its correct utilization for the purpose of their maintenance and fulfillment of the needs of the next generation. In this context, resilience in ecological dimension covers urban system capacities for coping with environmental threats such as flood, drought, and rapid urban changes, and self-organizing and continuing activities against them. Therefore, regular program should be developed and integrated urban management is needed for protecting ecosystem, and its related services, as well as conserving natural resources. As discussed in Figures 3 and 4, these two concepts are together conveyed and both concentrate on parameters that are conceptually similar but different in the period of their performance. Indeed, system capacities for self-organization and maintenance of system integrity are significant to long-term sustainable development.

\subsection{Results of Mashhad water resources analysis}

The analyses indicate that Mashhad urban development regardless of urban resilience and sustainable development principles has exerted devastating environmental impacts and has directly and/or indirectly caused hydrologic and geomorphologic changes in the region. Development of this city directly causes morphologic changes of watersheds, watercourses, and natural drainage patterns, which in turn results in surface inundations, flooding, and system non-resilience against natural disasters. Moreover, it indirectly makes reductions in underground water in successive aquatic years because of excessive use of water from underground water tables and reduction in their feeding and, subsequently, natural cover removal and impermeable level extension.

Accordingly, the findings demonstrate high vulnerability of Mashhad to events such as inundation and drought. Resilience, as suggested by Alberti and Marzluff [35], significantly affects ecosystem conservation, including natural water resources and natural cycles of water, and primarily creates balance between ecosystem services and human services. It can empower urban systems in order to cope with threats, reduce vulnerability, and organize themselves.

\subsection{Validation of the relationship between water resources management with resilience and sustainability}

The analysis of the similar cases that are successful in water resources management for urban resilience and future sustainability shows that a variety of activities are carried out for accomplishment of these objectives. The following are some of the most crucially practical samples which can be used in Mashhad according to their characteristics. Sadoff and Muller [36] concentrate on a combination of soft and hard strategies including knowledge and information retrieval, warning system establishment, and stronger management of institutions and infrastructures. These strategies make contribution to minimization of water cycle disorders affected by climate changes and urban development. Furthermore, they view water resource management as an integrated approach, which makes consumers aware of upcoming water resource challenges on the one hand and offers a framework for removing these challenges on the other hand. Water security investment is also one of the integrated long-term strategies for creating a resilient world.

Novtony et al. [37] suggest development and maintenance of natural drainage system in cities and conformity of urban drainage system with natural drainage patterns for the purpose of surface water absorption and improvement in underground water and examine the implemented plans. For example, Portland green street plan acts as natural drainage system through permeable green contexts in both sides of streets. Chicago green alley plan makes contribution to surface water conservation and its increasing permeability by using permeable materials and pipes for water movement. Benedict and McMahon [38], Harrison et al. [39], and Ahren [40] investigate the 
use of green infrastructures in urban development for supporting environmental processes and services and creating more sustainable and resilient conditions for urban environment. They describe green infrastructure as an integrated network of natural environments and other open spaces, which protects natural ecosystem functions and offers proper ways and means for surface water management. Rain gardens, downspout disconnection, bioswales, permeable pavements, green alleys and streets, green parking, and green roofs are instances of green infrastructures.

US Environmental Protection Agency (EPA) considers green infrastructures as a solution for improving water quality and flood control system, especially in Milwaukee [41]. Industrial park of Menomonee River is the largest green infrastructure in Milwaukee, which creates a recreative space and manages water floods.

Pilehvar and Pourahmad [42] evaluate growth and development of Iran's metropolises and their impacts upon environment. They describe frame density in urban development as one strategy for reducing these impacts. Jabareen [43] also introduces high-density patterns as the appropriate urban form in environmental terms during his analysis of sustainability of urban typologies. The findings of this study show that highdensity patterns bring about less negative effects upon energy, water, soil, and natural cover of lands and lead to higher environmental sustainability.

\section{Conclusion}

According to the performed analyses of Mashhad water resources and the related cases, this study puts forward the following suggestions for urban resilience and longterm sustainability plans. Some of these strategies are generalizable to similar cities and should be applied to their developments:

\section{Short-term Strategies:}

- Creating natural drainage system in urban development and coordination of urban drainage system with natural patterns (specifically in Mashhad);

- Use of Green infrastructure in urban development for surface water management;

- Rebuilding of the main natural channels in urban texture and determination of their limits (specifically in Mashhad);

- Increase in permeable surfaces through creation of green spaces and use of permeable materials in new developments (specifically in Mashhad);

- Use of alternative water resources and separation between industrial water resource consumption and urban water resource consumption.
Long-term Strategies:

- Creation of urban density patterns for avoiding waste of natural water resources, soil, natural cover of lands, etc. (specifically in Mashhad);

- Public training for heightening awareness of people about water crisis and creation of a proper environmental culture;

- Revisions in urban development designs (specifically in Mashhad); Planning for higher levels of public participation in natural resources conservation;

- Adoption of integrative approach for water management and specified planning of water resources for different consumptions.

Conservation of natural water cycles is one of the components, which should be considered for creating resilient and sustainable cities. In order to convey resilience and sustainability concepts, different social, environmental, physical, and other dimensions of urban regions should be taken into consideration. Corresponding measures should also be implemented. The above-mentioned strategies contribute to water resource conservation and natural water cycles, thus, making cities resilient against flood and drought. Thus, they are considered as an important step towards environmental sustainability. In addition to seeing cities as a set of systems and checking their sustainability and resilience in different dimensions, national macro-level policies and plans should be implemented at the first step. Creation of resilient and sustainable cities should be viewed as a national priority.

Building resilient cities as a national priority. Cities are complex and dynamic meta-systems in which technological components and social components interact. They are made up of dynamic linkages of physical and social networks. Planning for resilience in the face of urban disaster requires designing cities that combine seemingly opposite characteristics, including redundancy and efficiency, diversity and interdependence, strength and flexibility, autonomy and collaboration, and planning and adaptability. We are just beginning to realize the scope and magnitude of the challenges inherent in making our cities resilient to threats from natural hazards and urban terrorism. To meet these challenges, the authors propose a national resilientcities initiative aimed at the vision of the resilient city as the goal that bridges natural hazard mitigation and counterterrorism practice. To succeed in this initiative, changes in national disaster policy, funding for basic and applied urban systems research, support for advanced education programs, and active collaboration among the city planning, design, and construction professions will be required. This initiative should be comprised of: 
Basic and applied research. While we have learned a great deal about the behavior of various urban systems in recent years, there are still many gaps in our knowledge about how physical and social systems within cities respond to extreme stress. A national program of basic and applied research on this topic could generate valuable contributions to our understanding of how to plan and design resilient cities. The National Research Council [44] has listed a number of critical long-term research needs. The list notes the need for developing new ways of understanding and modeling for complex, adaptive systems. Urban planning researchers have made a promising start in this direction by using GIS to analyze, model, and visualize dynamic and interdependent urban systems such as linkages between land use and transportation [45]. The new GIS contingency models are able to respond to 'what if' questions that are asked about potential system responses to future changes of various types.

Education program. In concert with the research campaign, we need to strengthen education and training in designing and managing resilient urban systems. The goal, here, is to increase our pool of human resources to prompt future engineers, scientists, planners, and emergency managers to make practice and become educators and researchers. The National Research Council report recommends a human resource development program aimed at producing a sustained increase in baccalaureate and doctoral degrees in fields consistent with long-term priorities for homeland security [44]. Such program should include support of university training for students in disciplines that can contribute to urban resilience. These would include the physical science, social science, planning, design, and engineering and management fields. This program should be discussed in workshops to reach certain collaborations.

Professional collaboration. If we are to take the achievement of urban resilience seriously, we need to integrate the goal of resilient city into every practice of city planners, engineers, architects, emergency managers, developers, and other urban professionals. This requires a long-term collaborative effort to increase knowledge and awareness about resilient city planning and design. Prieto notes that, because engineering tends toward specialization, engineers have difficulty translating lessons learned to a broad range of disciplines; he suggests that the National Academy of Engineering could play an important role in disseminating lessons from disasters [46]. Other professions face similar difficulties and would benefit from both intra-professional and inter-professional collaborations. Such an effort could start with a summit conference to convene leaders of all the professions concerned with city design and development to develop resilient city in practice guidelines. This could be kicked off by a national conference on planning and building of Resilient Cities. The objective of the conference would be to discuss principles for building resilient cities and ways of incorporating these principles into the practice of engineers, planners, architects, administrator's developers, and other city designers, builders, and managers. The program would look at both physical and social systems, and their linkages.

\section{References}

1. Colten, C.E., Kates, R.W. and Laska, S.B. "Community resilience: Lessons from new Orleans and hurricane Katrina", CARRI Report 3, Oak Ridge National Laboratory, Community and Regional Resilience Initiative, Oak Ridge (2008).

2. Godschalk, D.R., Beatly, T., Berk, P., Brower, D.J. and Kaiser, E.J., Natural Hazard Mitigation: Recasting Disaster Policy and Planning, pp. 3-81, Island Press, Washington, D.C. (1999).

3. Beatly, T. "The vision of sustainable communities", In Cooperating with Nature: Confronting Natural Hazards with Land Use Planning for Sustainable Communities, R.J. Burby, Ed., Joseph Henry Press, Washington, D.C., pp. 233-262 (1988).

4. Vale, L.J. and Campanella, T.J. "The resilient city: trauma, recovery, and remembrance", http:// resilintcity.mit.edu http://videolectures.net/mitworld_resilient _city (09.18.2002).

5. Newman, P., Beatley, T. and Boyer, H., Resilient Cities: Responding to Peak Oil and Climate Change, Island Press, Washington D.C. pp. 1-15 (2009).

6. European Environment Agency, "The European environment - state and Outlook 2010 - urban environment", Report No 1/2010, Luxembourg: Publications Office of the European Union (2010).

7. International Council for Local Environmental Initiatives (ICLEI), "Resilient Communities Program Concept 2002", http://resilient-cities.iclei.org/bonn 2011/resilience-resource-point/glossary-of-key-termsresilient, (09.20.2011).

8. Mileti, D., Disaster by Design: A Reassessment of Cultural Hazards in the United States, Joseph Henry Press, Washington. D.C. pp. 32-33 (1999).

9. Foster, H.D., The Ozymandias Principles: Thirty One Strategies for Surviving Change, 1st Edn., Victoria, B.C: Southdown Press, Canada, pp. 5-80 (1997).

10. Bolin, R. and Stanford, L., The North Bridge Earthquake: Vulnerability and Disaster, Routledge Press, New York, pp. 4-61 (1998).

11. Comfort, L.K., Shared Risk: Complex Systems in Seismic Response, 1st Edn., Elsevier, Oxford, U.K. pp. 3-56 (1999). 
12. Tobin, G.A. "Sustainability and community resilience: The holy grail of hazards planning?", Int. J. of Global Environmental Change Part B: Environmental Hazards, 1(1), pp. 13-25 (1999).

13. Newman, P. "Towards the resilient city", http://www. dac.dk/en/dac-cities/sustainable-cities/experts/peter -newman-towards-the-resilient-city (01.21.2014).

14. Siemens, ARUP, RPA "Toolkit for resilient cities: infrastructure, technology and urban planning", http://acccrn.net/resources/toolkit-resilient-c ities -infrastructure-technology-and-urban-planning (02.2013).

15. International Council for Local Environmental Initiatives (ICLEI) "Background paper for the Council of Europe's report on resilient cities", http://www.icleieurope.org (01.26.2012).

16. Schwartz, E. "A needless toll of natural disasters", Op-Ed, Boston Globe, http://reliefweb.int/report/ philippines/needless-toll-natural-disasters (03.23.2006).

17. "The global footprint network", http//www.footprintnetwork,org/en/index, php/GFN/page/world foot print/ (08.29.2015).

18. Cutter, S.L., Barnes, L., Berry, M., Burton, C., Evans, E., Tate, E. and Webb, J. "A place-based model for understanding community resilience to natural disasters", Int. J. of Global Environmental Change, 18(4), pp. 598-606 (2008).

19. Bergamini, N., Blasiak, R. and Eyzaguirre, P.B. "Indicators of resilience in socio-ecological production landscapes (SEPLs)", Report of UNU-IAS policy, United Nations University Institute of Advanced Studies, Yokohama (2013).

20. Sharifi, A. and Yoshiki, Y. "Major principles and criteria for development of an urban resilience assessment index", Int. Conf. and Utility Exhibition 2014 on Green Energy for Sustainable Development (ICUE), Pattaya, Thailand, pp. 1-5 (2014).

21. Bahreini, S.H. "Urban planning and sustainable development", J. of Rahyaft, 17, pp. 28-40 (1997) (In Persian).

22. Pourjafar, M., Khodaee, Z. and Pourkheiri, A. "Analytical approach to identify the components, indicators and dimensions of sustainable urban development", $J$. of Iranian Social Development Studies, 3(3), pp. 25-36 (2011) (In Persian).

23. Department of Economic and Social Affairs of the United Nations, "Sustainable development challenges", Repot of World Economic and Social Survey, United Nations Publication, New York (2013).

24. Municipality of Mashhad, Statistic Report of Mashhad City, Planning and development Department of Mashhad Municipality, Mashhad, Iran pp. 40-68 (2013). (In Persian).

25. Farnahad Consulting Engineers, "Development and Reconstruction Plan (Inclusive) of Mashhad, Basic studies of human and activities; population", Submitted to Ministry of Housing and Urban Planning, General Office of Housing and Urban Planning of Khorasan Province, pp. 4-22 (2009) (In Persian).

26. Iran National Center of Statistics, Report of General Population and Housing Census (2011) (In Persian).

27. Pourahmad, A., Hoseini, S.A. and Hoseini, S.M. "Physical development of Mashhad city in the recent decades and its impacts on water reserves", J. of Human Geography Research, 46(3), pp. 485-504 (2012) (In Persian).

28. Azami, H., Abasnia, M., Shakerizaree, H., Saberiiraj, Z. and Hoseinpour, A. "Adverse impacts of Mashhad physical development in the context of the natural environment", 4th Conf. on Urban Planning and Management, Mashhad, Iran, pp. 130-1143 (2012) (In Persian).

29. Hoseinzade, S.A. and Jahaditoroghi, M. "The effects of Mashhad development on the natural drainage pattern and intensification of urban floods", J. of Geographical Research, 39(9), pp. 145-159 (2008) (In Persian).

30. Naghshan Consulting Engineers, "Strategic Plan of Reorganization watercourse in Mashhad City, the second studies", submitted to Mashhad Municipality, Department of City Planning and Architecture, pp. 132-174 (2007) (In Persian).

31. Dolati, J. "Environmental effects Mashhad development on watershed and water resources", 5th Nat'l Cong. of Civil Engineering, Mashhad, Iran, pp. 148154 (2010) (In Persian).

32. Farnahad Consulting Engineers, "Development and reconstruction plan (inclusive) of Mashhad, environmental basic studies", submitted to Ministry of Housing and Urban Planning, General Office of Housing and Urban Planning of Khorasan Province, pp. 58-61 (2009) (In Persian).

33. Hoseini, S.A. "The analyzing of Mashhad city sprawl and its effect on the soil and water resources", M.A. Thesis in Geography and Urban Planning, University of Tehran, Iran (2008) (In Persian).

34. Khorasan Razavi Regional Water Company, Report of Water Resources in Mashhad, Study Affairs (2012) (In Persian)

35. Alberti, M. and Marzluff, J.M. "Ecological resilience in urban ecosystems: linking urban patterns to human and ecological functions", Int. J. of Urban Ecosystems, 7(3), pp. 241-265 (2004).

36. Sadoff, C.W. and Muller, M., Better Water Resources Management-Greater Resilience Today, More Effective Adaptation Tomorrow, GWP TEC Perspectives Paper, CPWC's publication, Stockholm pp. 1-17 (2009).

37. Novotny, V., Ahern, J. and Brown, P., Water Centric Sustainable Communities: Planning, Retrofitting and Building the Next Urban Environment, 1st Edn., John Wiley \& Son Press, New Jersey, USA, pp. 135176(2010). 
38. Benedict, M.A. and McMahon, E.T., Green Infrastructure: Linking Landscapes and Communities, Island Press, Washington, D.C pp. 1-57 (2006).

39. Harrison, P., Bobbins, K., Culwick, C., Humby, T.L., La Mantia, C., Todes, A. and Weakley, D. "Urban resilience thinking for municipalities", Rreport 1901 MR, University of the Witwatersrand, pp. 52-67 (2014).

40. Ahern, J. "Green infrastructure, a spatial solution for cities," In Cities of the Future: Towards Integrated Sustainable Water and Landscape Management, V. Novotny and P. Brown, Eds., IWA Publishing, London, UK, pp. 267-283 (2007).

41. United States Environmental Protection Agency (EPA), "Water: Green infrastructure", http://water. epa.gov/infrastructure/greeninfrastructure/ (06.13.2014).

42. Pilevar, A.A. and Pourahmad, A. "Growth and development of Iran metropolitan cities: A case study Mashhad", J. of Geography Research, 36(2), pp. 103121 (2004). (In Persian).

43. Jabareen, Y.R. "Sustainable urban forms their typologies, models, and concepts", J. of Planning Education and Research, 26(1), pp. 38-52 (2006).

44. National Research Council Making the Nation Safer: The Role Science and Technology in Countering Terrorism, National Academies Press, Washington, D.C. pp. 357-371 (2002).

45. Brail, R.K., Planning Support System: Integrating Geographic Information Systems, Models, and Visualization Tools, R.E. Klosterman, Ed., ESRI Press, New York, pp. 99-201 (2001).

46. Prieto, R., "A 911 call to the engineering profession", Int. J. of The Bridge, 32(1), pp. 18-22 (2002).

\section{Biographies}

Manouchehr Tabibian received his MS degree in Architecture in 1966, PhD degree in City Planning in 1973 from University of Tehran, Iran, and MS degree in Regional Science from University of Pennsylvania in 1978. He is an Emeritus Professor of urban design and city planning. $\mathrm{He}$ is teaching in the College of Fine Arts at University of Tehran and in the Faculty of Architecture and City Planning of the Islamic Azad University of Qazvin. He, as an architect and city planner, has over 40 years of local and international experience in Iran and in Sydney of Australia. His research interest includes planning, design, and methods of resiliency and sustainability of cities with emphasis on urban form and design issues. He has published over 14 books and 40 papers in various journals and presented many others at national and international conferences. Since September 2014, he has had the honor of being the Editor in Chief of the Journal of Space Ontology in the Faculty of Architecture and City Planning at University of Qazvin.

Sepideh Movahed received her BS degree in Architecture from Islamic Azad University of Mashhad, Iran, in 2008, and an MS degree in Urban Design from Tehran University, Kish branch, Iran, in 2010. She is currently a PhD degree student at Islamic Azad University of Qazvin. Her research interests include resiliency, ecological design, urban environment, and urban morphology. She has published and presented many papers in various ISC Journals and at many national and international conferences in her interested subject. 